\title{
Dementia management: a brief overview for primary care clinicians
}

Ngar Yee $\underline{\text { Poon }}^{1}$, MMed, MRCPsych, Chun How $\underline{O o j}^{2}$, MBBS, MRCP, Choon How $\underline{H o w}^{3,4}$, MMed, FCFP, Peng Soon $\underline{\text { Yoon }}^{2}$, MBBS, MRCP

Andre accompanied his grandfather to your clinic for a regular follow-up. His family had encouraged them to seek your advice, as his family doctor, about the options that could help his grandfather's dementia. Andre's grandfather had initially refused any treatment, but has now agreed to discuss the available treatment options.

\section{WHAT IS DEMENTIA?}

Dementia presents with a progressive and irreversible decline in cognitive abilities, including memory, language and thinking skills, which is severe enough to interfere with daily function. The March 2018 Singapore Medical Journal article titled 'Approach to the forgetful patient' explained how to make the diagnosis of dementia and its epidemiology. ${ }^{(1)}$

\section{HOW RELEVANT IS THIS TO MY PRACTICE?}

The worldwide prevalence of dementia in 2015 was estimated to be 46.8 million and is projected to double, reaching 75 million in $2030 .^{(2)}$ In Singapore, it is projected that there will be 53,000 people aged 60 years or older living with dementia by $2020 .{ }^{(3)}$

Care of patients with dementia remains a challenge in primary care. In the context of a busy primary care setting, it may be difficult to diagnose dementia and its management can be complex. ${ }^{(4)}$ However, it is possible for the family physician to diagnose and manage the straightforward cases in conjunction with the patient's other chronic diseases in order to provide holistic and personalised care. This article gives an overview of the management of dementia with input from the specialties of geriatric medicine, psychological medicine and family medicine. The main objectives of management are to improve the quality of life of patients, maximise or maintain their functional independence, and minimise family or caregiver stress.

\section{WHAT CAN I DO IN MY PRACTICE? Pharmacological management}

The first question often asked by the patient's caregivers and families is, 'Is there any medicine to treat dementia?' Cognitive enhancers refer to two types of medications, acetylcholinesterase inhibitors and N-Methyl-D-aspartate (NMDA) receptor antagonists. These are indicated for Alzheimer's disease and produce modest but significant therapeutic benefits by regulating neurotransmitter function to maintain cognitive function. ${ }^{(5,6)}$ However, they are not a cure for dementia and do not alter the underlying disease process. In view of their modest efficacy, potential side effects and high cost, a thorough discussion with the patient and family is recommended. Primary care physicians need to ensure that patients and their family members have a good understanding of the illness as well as the pros and cons of the medicine being offered. These medications, their common side effects and special characteristics are shown in Table I. Other adjuncts or supplements for dementia are the activated form of Gingko biloba (EGb 761) and Tebonin forte, which has some evidence of efficacy. ${ }^{(7)}$ Vitamin E, multivitamins, Omega 3, noni juice and organic virgin coconut oil have shown no significant benefits.

Aside from the aforementioned medications, the clinician should aim to optimise the patient's chronic disease management to decrease the risk of a cardiovascular event. This includes controlling blood pressure and diabetes mellitus, treating hyperlipidaemia, prescribing antiplatelet drugs when needed and advising smokers to quit smoking. Regular exercise is also recommended. ${ }^{(8)}$

Monitoring patient response depends on subjective (family observation) and objective (physician observation and cognitive score trend) parameters. As the natural history of Alzheimer's disease is a progressive gradual decline, patients are considered to be responding if they appear to be largely stable on the drug over the subsequent months and years. It should also be noted that patients with dementia may develop comorbid depression. Hence, their mood should be monitored, especially if there is a change in condition such as worsening cognition or new behavioural issues. In cases of doubt, a therapeutic trial of an antidepressant, such as a selective serotonin reuptake inhibitor, is reasonably safe.

\section{Non-pharmacological management}

For patients with dementia, non-pharmacological interventions should be the first-line management. In severe cases, nonpharmacological intervention also has a valuable adjunctive role with pharmacological treatment. As primary care physicians

${ }^{1}$ Department of Psychological Medicine, ${ }^{2}$ Department of Geriatric Medicine, ${ }^{3} \mathrm{C}$ are and Health Integration, Changi General Hospital, ${ }^{4}$ Family Medicine Academic Clinical Programme, SingHealth Duke-NUS Academic Medical Centre, Singapore

Correspondence: DrPoon NgarYee, Consultant, Department of Psychological Medicine, Changi General Hospital, 2 Simei Street3, Singapore 529889. ngar_yee_poon@cgh.com.sg 
Table I. Characteristics and side effects of medication for dementia.

\begin{tabular}{|c|c|c|c|}
\hline Drug & Dose & Common side effects & Comments \\
\hline \multicolumn{4}{|c|}{ Acetylcholinesterase inhibitors } \\
\hline Donepezil & $\begin{array}{l}5 \mathrm{mg} O \mathrm{~N}, \text { increase to } 10 \mathrm{mg} \mathrm{ON} \\
\text { after } \geq 4 \mathrm{wk}\end{array}$ & \multirow{2}{*}{$\begin{array}{l}\text { Oral medicines: nausea, } \\
\text { vomiting, diarrhoea, } \\
\text { bradycardia }\end{array}$} & \multirow{3}{*}{$\begin{array}{l}\text { - Contraindicated in bradycardia; } \\
\text { exercise caution in peptic ulcer } \\
\text { disease } \\
\text { - Donepezil: Aricept is orodispersible. } \\
\text { A generic version of donepezil is now } \\
\text { available } \\
\text { - For gastrointestinal side effects, } \\
\text { stop for a week, then restart; some } \\
\text { patients may tolerate the drugs on } \\
\text { re-challenging }\end{array}$} \\
\hline Rivastigmine capsule & $1.5 \mathrm{mg} \mathrm{BD}$, titrate to $6 \mathrm{mg} \mathrm{BD}$ & & \\
\hline $\begin{array}{l}\text { Rivastigmine } \\
\text { patch (transdermal) }\end{array}$ & $\begin{array}{l}\text { Exelon Patch } 5 \text {, increase to Patch } \\
10 \text { after } \geq 4 \mathrm{wk}\end{array}$ & $\begin{array}{l}\text { Skin patch (Exelon): rash, } \\
\text { itch; fewer gastrointestinal } \\
\text { side effects }\end{array}$ & \\
\hline \multicolumn{4}{|c|}{ NMDA receptor antagonist } \\
\hline Memantine & 5-20 mg daily (titrate from $5 \mathrm{mg}$ ) & $\begin{array}{l}\text { Headache, giddiness; } \\
\text { constipation at higher doses; } \\
\text { rarely paradoxical insomnia }\end{array}$ & $\begin{array}{l}\text { - Approved for moderate to severe } \\
\text { Alzheimer's disease; can be used as } \\
\text { monotherapy or in combination with } \\
\text { donepezil } \\
\text { - If creatinine clearance }<30 \mathrm{~mL} / \mathrm{min} \text {, } \\
\text { max } 10 \mathrm{mg} \text { daily }\end{array}$ \\
\hline
\end{tabular}

BD: twice a day; NMDA: N-Methyl-D-aspartate; ON: every night

are often pressed for time, brief and effective tips can be given to patients and caregivers during their short clinic consults to help manage the condition. Firstly, the diagnosis of dementia should be explained to the patient (if possible) and family. They should also be told about the complications of the disease, which include impairment in activities of daily living and behavioural issues. Expectations should be carefully managed, as dementia is irreversible and will eventually progress from the mild to the moderate and severe stages.

\section{Regular structured routine}

Structured daily activities, including regular gentle exercise and cognitive activities such as playing mahjong and puzzle-solving, would help patients with dementia to maintain mental function. Patients and caregivers can also leverage technological devices such as tablet and smartphone applications. A structured daily routine not only enriches and adds meaning to their lives, but also helps to prevent the patient from taking too many daytime naps.

\section{Sleep hygiene}

In patients with dementia, sleep requirement varies from individual to individual. While some only need as little as four hours of sleep, others may need up to 11 hours. In patients with dementia, insomnia is common and often distressing to families, especially if associated with inappropriate activities or noisy behaviour. Good sleep hygiene helps both dementia patients and their caregivers to have more energy to face their daytime demands. Some sleep advice that can be provided includes:

- Lifestyle: Besides keeping to a regular routine and structured lifestyle to minimise naps, there should also be a schedule that helps patients to relax before bedtime. Possible ideas include taking a warm bath or playing some soothing music. The importance of a regular sleep schedule should be emphasised. Doctors should advise patients to avoid taking daytime naps if possible. In the event that the patient needs a nap, he should avoid taking it late in the day and restrict it to less than 20 minutes. In addition, regular gentle exercise and avoiding stimulants such as caffeine also help with ensuring a good night's sleep.

- $\quad$ Environment: Check whether patients' environment is conducive to sleeping. Minimising the noise level and keeping the bedroom dark would make it less likely for sleep to be interrupted.

- $\quad$ Medical illness: Physical illnesses such as gastric reflux with heartburn, respiratory disease, and chronic pain or itch, as well as psychological illnesses such as anxiety, would affect sleep quality, and these issues should be appropriately addressed.

\section{Reminiscence and other activities}

Patients with Alzheimer's disease most commonly present with initial loss of short-term memory while being able to recall older memories. Reminiscing activities can help seniors with dementia feel contented and peaceful, reduce stress and enhance positive feelings, which can improve their mood, reduce agitation and minimise challenging behaviours such as wandering. These activities must be individualised based on the patient's past hobbies, interests and occupations. Some tips for home reminiscing activities include: (a) listening to the patient's favourite music; (b) looking through old keepsake items or photos; and (c) tactile art and craft activities such as painting or pottery to spark good memories. Simple, fail-proof art and craft work would be useful if the patient enjoyed these activities in the past. Other ways to spark memories using touch include allowing the patient to wear or touch items that would bring up pleasant memories. For example, patients who used to enjoy taking care of babies can be given a baby doll to hold.

\section{Cognitive impairment-related safety issues}

Safety issues such as wandering out of the house, getting lost or forgetting to switch off the gas can be risky for both 
patients and their families. It is therefore important to address these issues by designing an environment that allows patients to continue living safely at home. Some simple tips to give to family members for managing patients' wandering issues include: (a) advising the family to put clear words or symbols around the patient to help him to re-orientate, especially if he has trouble remembering the date or location; and (b) in cases where the patient is at risk of leaving, it is advisable to have him wear an identity necklace or bracelet with a contact number. The Alzheimer's Disease Association offers a Safe Return Card programme to address wandering issues. Alternatively, family members can link the patient's mobile phone to a GPS (Global Positioning System) tracking system to locate the patient when he is lost.

Home safety issues should also be considered. Giving advice on kitchen safety issues is essential for patients and their families. It is advisable to use an electric cooker instead of a gas cooker. They should also consider purchasing appliances that can turn off automatically. Home safety devices such as smoke and carbon monoxide detectors should be installed. To help ensure that medications are taken, a pill box organiser provides a helpful reminder. Other safety measures include ensuring that excess medications are kept in a locked drawer. All cleaning products such as detergents have to be secured and locked. The family should also be advised to keep a list of emergency contact numbers that is visible to the patient if help is required.

\section{Shared care programme}

Many patients who suffer from dementia may wish to continue seeing a general practitioner or polyclinic doctor, and it is possible for them to be managed at the primary care level. For example, some polyclinics run memory clinics for patients with memory problems, such as those in Ang Mo Kio, Bedok, Choa Chu Kang, Hougang, Tampines and Yishun.

\section{Community support and resources for caregivers}

Being a caregiver to patients with dementia can be challenging at times. More educational awareness and support from the community would help to relieve some of the stress and prevent caregiver burnout. The Alzheimer's Disease Association provides education and support services to people with dementia and their caregivers. Tsao Foundation provides training and workshops for caregivers, while SAGE (Singapore Action Group for Elders) offers a hotline for problems related to the elderly. There are day care centres that provide day activity programmes, some of which are specially catered to patients with dementia. Examples are Apex Harmony Lodge, New Horizon Centre, Sunlove Home's Dementia Day Care Centre and SWAMI Home. More information on resources can be found at the Agency for Integrated Care website (https://www.aic.sg).

For patients who would benefit from specialist input, many hospitals such as Institute of Mental Health and Changi General Hospital, Singapore, provide a psychogeriatric service that assesses and manages patients with dementia. The multidisciplinary team consists of geriatric psychiatrists, geriatric and psychiatric nurses, clinical psychologists, medical social workers, occupational therapists and physiotherapists. The team also runs a community outreach programme that provides training to community partners, onsite mental health assessments and interventions for elderly patients who live in the community.

Primary care physicians may also encounter issues related to Lasting Power of Attorney and Advance Care Planning when managing patients with dementia. There are many useful online resources to help them to gain an in-depth understanding in these areas, including: Singapore Silver Pages, Lasting Power of Attorney (https://www.silverpages.sg/caregiving/Lasting\%20 Power\%20of\%20Attorney); Singapore Medical Journal, Not that way: Advance Care Planning ${ }^{(9)}$ (http://www.smj.org.sg/article/ not-way-advance-care-planning); and Singapore Silver Pages, Advance Care Planning (https://www.silverpages.sg/caregiving/ Advance\%20Care\%20Planning).

\section{CONCLUSION}

In summary, primary care physicians have much to offer to patients who suffer from dementia. Appropriate care, treatment and support significantly lessens both patient and caregiver stress and helps to promote their ability to live an active and meaningful life.

\section{TAKE HOME MESSAGES}

1. Management of dementia usually needs a multidisciplinary approach beyond medication alone.

2. Dementia medicine consists of two groups, acetylcholinesterase inhibitors and NMDA receptor antagonist.

3. As dementia medications have modest but significant efficacy, it is encouraged to discuss the risks and benefits with the patient and family.

4. Non-pharmacological management such as regular structured routine, good sleep hygiene, reminiscence and other activities can help to improve the well-being of dementia patients.

5. Caregivers and family members should be advised to watch out for the patients' safety at home and outdoors, as they have poor safety awareness.

6. Physicians can consider a referral to a memory clinic or specialist clinic if indicated.

7. The Alzheimer's Disease Association, Tsao Foundation and SAGE are some organisations that provide education and support for dementia care in the community.

You explored many options with Andre and his grandfather. Andre was thankful for the lifestyle tips they could try at home. He also mentioned that it was very useful to learn about community resources such as day care centres. As Andre's wife was the main caregiver for his grandfather, they would help relieve the caregiver stress his wife was facing. 
ABSTRACT With the increasing life expectancy and ageing population in Singapore, we are likely to see more patients with dementia seeking help from their primary care clinicians. Acetylcholinesterase inhibitors and N-Methyl-Daspartate receptor antagonists for dementia management can be costly given their modest efficacy, and it is important to discuss the risks and benefits with patients before a shared decision is made. Non-pharmacological management such as regular structured routine, good sleep hygiene, reminiscence and other activities are also useful in improving the well-being of dementia patients. Caregivers and family members can be advised on what to watch out for to keep patients safe at home and outdoors, as dementia patients have poor safety awareness. The primary care clinician can manage depression, if present, and refer the patient to memory clinics or appropriate specialist clinics for further assessment when indicated.

Keywords: cognitive dysfunction, dementia, neurocognitive disorders, primary health care, treatment and management

\section{REFERENCES}

1. Yoon PS, Ooi $\mathrm{CH}$, How $\mathrm{CH}$. Approach to the forgetful patient. Singapore Med J 2018; 59:121-5.

2. Alzheimer's Disease International Dementia statistics [online]. Available at: https://www.alz.co.uk/research/statistics. Accessed May 22, 2018.

3. Alzheimer's Disease International, Alzheimer's Australia. Dementia in the Asia Pacific Region [online]. Available at: https://www.alz.co.uk/adi/pdf/DementiaAsia-Pacific-2014.pdf. Accessed February 23, 2018.

4. Pimlott NJG, Persaud M, Drummond N, et al. Family physicians and dementia in Canada. Part 2. Understanding the challenges of dementia care. Can Fam Physician 2009; 55:508-9.e07.

5. Birks J. Cholinesterase inhibitors for Alzheimer's disease. Cochrane Database Syst Rev 2006; (1):CD005593.

6. McShane R, Areosa Sastre A, Minakaran N. Memantine for dementia. Cochrane Database Syst Rev 2006; (2):CD003154.

7. Gauthier S, Schlaefke S. Efficacy and tolerability of Ginkgo biloba extract EGb $761 \circledR$ in dementia: a systematic review and meta-analysis of randomized placebo-controlled trials. Clin Interv Aging 2014; 9:2065-77.

8. Ministry of Health, Singapore. Dementia. $\mathrm{MOH}$ Clinical Practice Guidelines 1/2013 [online]. Available at: https://www.moh.gov.sg/content/dam/moh_web/ HPP/Doctors/cpg_medical/current/2013/Dementia/Dementia\%2010\%20 Jul\%202013\%20-\%20Booklet.pdf. Accessed May 22, 2018.

9. How $\mathrm{CH}$, Koh LH. Not that way: Advance Care Planning. Singapore Med J 2015; 56:19-22. 


\section{SINGAPORE MEDICAL COUNCIL CATEGORY 3B CME PROGRAMME}

\section{(Code SMJ 201806A)}

1. Cognitive impairment is a hallmark symptom of Alzheimer's disease.

2. Dementia presents with a progressive and irreversible clinical syndrome of cognitive decline that is severe enough to interfere with daily function.

3. Optimal dementia care remains a challenge in primary care, as diagnosis and management in the primary care setting is complex and often involves a multidisciplinary approach.

4. The aim of primary care management of dementia is to start and optimise the dose of cholinesterase inhibitors, and does not involve monitoring quality of life or minimising caregiver stress.

5. Both acetylcholinesterase inhibitors and the N-Methyl-D-aspartate receptor antagonist are medications licensed for management of Alzheimer's disease.

6. Before starting medication for patients with Alzheimer's disease, it is essential to have a thorough discussion with the patient and the family, to ensure that they have a good knowledge of the illness and understand the pros and cons of pharmacological and non-pharmacological treatments.

7. Donepezil has a generic version available, but is contraindicated in patients with bradycardia.

8. If rivastigmine is stopped due to side effects such as nausea, vomiting and diarrhoea, the clinician should never consider re-challenging the patient with rivastigmine.

9. The maximum $20 \mathrm{mg}$ daily dose of memantine can be safely prescribed to patients whose creatinine clearance is less than $30 \mathrm{~mL} / \mathrm{min}$.

10. Supplements for dementia, such as Gingko biloba, vitamin E, multivitamins, Omega 3, noni juice and organic virgin coconut oil, have all demonstrated some significant benefits for patients with dementia.

11. Involving the family or caregiver in monitoring the drug response can supplement the physician's clinical assessment and cognitive score trend.

12. Optimising chronic disease management to decrease the risk of any new cardiovascular event is part of good management for patients with dementia.

13. Primary care physicians should provide information on non-pharmacological interventions to patients and their caregivers, as it is part of the first-line management for dementia.

14. Advocating not keeping to any regular structured routine is important to stimulate the patient's mental functions and retard the progression of dementia.

15. Active screening and management of other illnesses, such as gastric reflux with heartburn, respiratory disease and psychological illness, will improve sleep quality for patients with dementia.

16. Reminiscing activities need not be individualised based on past hobbies, interests and occupations

17. Cognitive impairment can result in safety risks for both patients and their families, such as patients wandering out of the house, or leaving a lighted stove on and leaving the house.

18. A simple tip for family members to manage patients' wandering issue includes giving them clear words or symbols to re-orientate or remind them of common destinations and locations.

19. Medication adherence and safety can be enhanced with the use of a pill box organiser to organise patients' long-term medications.

20. The family or caregivers should make a list of emergency contact numbers that is easily accessible to patients when they require help.

True False

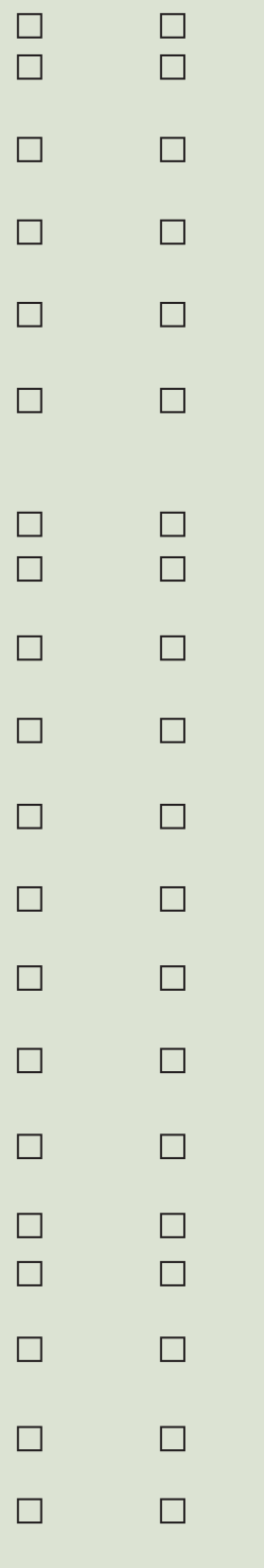

\section{Doctor's particulars:}

Name in full:

Specialty:
MCR no.:

Email:

\section{SUBMISSION INSTRUCTIONS:}

Visit the SMJ website: http://www.smj.org.sg/current-issue and select the appropriate quiz. You will be redirected to the SMA login page.

For SMA member: (1) Log in with your username and password (if you do not know your password, please click on 'Forgot your password?'). (2) Select your answers for each quiz and click 'Submit'.

For non-SMA member: (1) Create an SMJ CME account, or login with your SMJ CME username and password (for returning users). (2) Make payment of SGD 21.40 (inclusive of $7 \%$ GST) via PayPal to access this month's quizzes. (3) Select your answers for each quiz and click 'Submit'.

RESULTS:

(1) Answers will be published online in the SMJ August 2018. (2) The MCR numbers of successful candidates will be posted online at the SMJ website by 6 August 2018. (3) Passing mark is $60 \%$. No mark will be deducted for incorrect answers. (4) The SMJ editorial office will submit the list of successful candidates to the Singapore Medical Council. (5) One CME point is awarded for successful candidates. (6) SMC credits CME points according to the month of publication of the CME article (i.e. points awarded for a quiz published in the December 2017 issue will be credited for the month of December 2017, even if the deadline is in January 2018).

Deadline for submission: (June 2018 SMJ 3B CME programme): 12 noon, 30 July 2018. 